\title{
Individual and contextual factors influencing dental health care utilization by preschool children: a multilevel analysis
}

\section{Chaiana PIOVESAN(a) \\ Thiago Machado ARDENGHI(b) Fausto Medeiros MENDES(c) Bernardo Antonio AGOSTINI(d) Edgard MICHEL-CROSATO(e)}

\footnotetext{
(a)Faculdade São Lucas, Porto Velho, RO, Brazil.

(b) Universidade Federal de Santa Maria - UFSM, Department of Stomatology, Santa Maria, RS, Brazil.

(c) Universidade de São Paulo - USP, School of Dentistry, Departament of Pediatric Dentistry, São Paulo, SP, Brazil.

(d) Universidade Federal de Pelotas - UFPel, School of Medicine, Departament of Epidemiology, Pelotas, RS, Brazil.

(e) Universidade de São Paulo - USP, School of Dentistry, Departament of Social Dentistry, São Paulo, SP, Brazil.
}

Declaration of Interest: The authors certify that they have no commercial or associative interest that represents a conflict of interest in connection with the manuscript.

Corresponding Author:

Chaiana Piovesan

E-mail: chaia-piovesan@hotmail.com

http://doi.org/10.1590/1807-3107BOR-2017.vol31.0027
Abstract: The effect of contextual factors on dental care utilization was evaluated after adjustment for individual characteristics of Brazilian preschool children. This cross-sectional study assessed 639 preschool children aged 1 to 5 years from Santa Maria, a town in Rio Grande do Sul State, located in southern Brazil. Participants were randomly selected from children attending the National Children's Vaccination Day and 15 health centers were selected for this research. Visual examinations followed the ICDAS criteria. Parents answered a questionnaire about demographic and socioeconomic characteristics. Contextual influences on children's dental care utilization were obtained from two community-related variables: presence of dentists and presence of workers' associations in the neighborhood. Unadjusted and adjusted multilevel logistic regression models were used to describe the association between outcome and predictor variables. A prevalence of $21.6 \%$ was found for regular use of dental services. The unadjusted assessment of the associations of dental health care utilization with individual and contextual factors included children's ages, family income, parents' schooling, mothers' participation in their children's school activities, dental caries, and presence of workers' associations in the neighborhood as the main outcome covariates. Individual variables remained associated with the outcome after adding contextual variables in the model. In conclusion, individual and contextual variables were associated with dental health care utilization by preschool children.

Keywords: Dental Health Services; Multilevel Analysis; Child; Oral Health. 


\section{Introduction}

Unequal dental health care utilization by preschool children has been demonstrated in developing countries. ${ }^{1,2,3,4}$ Previous studies have suggested that some individual factors, such as being older, having a higher income, having one's own house, having access to preventive oral health information, having better educated parents, and being white children, could explain the reasons for seeking dental care services. ${ }^{3,4,5,6,7}$ Nevertheless, recent studies have demonstrated the importance of contextual factors for different oral health outcomes, including the use of dental services. ${ }^{8,9,10,11,12}$

In Brazil, the latest official publication showed regional inequality in dental care utilization (SBBRASIL 2010). It is suggested that the economic and social attributes of the community might influence dental care utilization by people who reside in it. ${ }^{12}$ Some recent evidence suggests that contextual determinants, such as a higher dentist-to-population ratio, influence dental care utilization by the population. ${ }^{12}$

Taking into account, risk for several conditions in individuals living in a community could be influenced by community context. Therefore, contextual and individual determinants have been used together in multilevel analyses. This allows adjusting individual characteristics by the contextual determinants of communities. ${ }^{5,13,14}$ Presently, few studies use multilevel analysis to assess individual and contextual factors for dental care utilization., ${ }^{5,10}$ Moreover, only one study was carried out with preschool children, showing that the use of dental care utilization was associated with individual factors (demographic, dental health, habits, and socioeconomic factors) and with contextual variables (dental care model). ${ }^{5}$ However, new studies are necessary to investigate other contexts in other regions.

Therefore, the aim of this study is to investigate the effect of contextual factors on dental care utilization after adjustment for individual characteristics of Brazilian preschool children.

\section{Methodology}

\section{Ethics approval}

This study was approved by the Research Ethics Committee of the Federal University of Santa Maria and of the School of Dentistry of University of São Paulo, Brazil. A written informed consent was obtained from all parents.

\section{Study design and data collection}

A cross-sectional study was performed with preschool children aged 1 to 5 years from Santa Maria, a town in Rio Grande do Sul State, located in southern Brazil. The sample size was calculated as follows: $5 \%$ standard error, $80 \%$ power, $95 \%$ confidence interval, $10 \%$ non-response rate, $2: 1$ ratio of unexposed to exposed subjects, and a prevalence ratio to be detected of at least 1.8. Moreover, the sample design was adjusted to 1.4 (design effect). The minimum sample size was estimated at 456 children. ${ }^{4}$ As the present study was part of a survey in which other outcomes were considered, the final sample size was greater than the minimum required.

Participants were randomly selected from children attending the National Children's Vaccination Day. Fifteen health centers were selected for this research and all of them were equipped with a dental chair. These were the largest health centers in town and more than $85 \%$ of the children were vaccinated in these centers during the study.

Fifteen examiners and 30 assistants performed the clinical examination and administered the questionnaire. They had been trained and calibrated before data collection. More information about the methodology and data obtained in this epidemiological survey can be accessed in previous publications. ${ }^{4,15,16}$

Children were examined for dental caries in a dental chair. Visual examinations followed the ICDAS criteria. ${ }^{17,18}$ As the ICDAS criteria are comparable with standard criteria (WHO) in an epidemiological survey of preschool children, ${ }^{19}$ we used the ICDAS cutoff point of 3 (0-2 sound, 3-6 carious) to calculate the decayed/missing/filled teeth $(\mathrm{dmft})$ index. Only severity criteria were used for the analysis. In other words, only teeth with frank cavitation were considered. The sample was dichotomized into decayed teeth $>4$ and decayed teeth $\leq 4$.

\section{Individual-level independent variables}

A structured questionnaire was used to obtain individual data such as demographic variables, 
socioeconomic factors, and data on dental health care utilization. The parents answered questions about age, children's sex, race (black or white), ${ }^{20}$ family income (less than 1 Brazilian minimum wage (BMW), between 1 and 2 BMW, between 2 and 3 $\mathrm{BMW}$, and more than $3 \mathrm{BMW}$ ) parents' schooling ( $\geq 8$ years of formal education or $<8$ years of formal education) and mothers' participation in their children's school activities (yes or no).

\section{Contextual independent variables}

Two community-related variables were used to assess the contextual influences on children's dental care utilization: presence of dentists and presence of workers' associations in the neighborhood (yes or no). These covariates have been previously used as community factors and community-related variables. ${ }^{12,13}$

\section{Outcome variable}

The outcome was measured by a question from the questionnaire: "Has your child ever visited a dentist?" (Yes or No).

\section{Data analysis}

The STATA 12.0 software (Stata Corporation, College Station, USA) was used for data analysis. Unadjusted and adjusted multilevel logistic regression models were used to describe the association between outcome and predictor variables. The odds ratio (OR) and the respective $95 \%$ confidence intervals $(95 \% \mathrm{CI})$ were calculated.

In the analysis, children (first level) were nested in neighborhoods (i.e., one of the 15 health centers) (second level). In the first stage, an unconditional model ('null' model) estimated the basic partition of data variability between two levels before individual and community characteristics were taken into account. ${ }^{21}$ The second model (Model 2) added covariates at the individual level; the "full" final model (Model 3) included individual factors and contextual covariates. Variables with a $p$-value $\leq 0.20$ in the unadjusted analyses were entered into the adjusted models. They were retained and considered statistically significant in the final models only if they had a p-value $\leq 0.05$ after adjustment.

\section{Results}

A total of 639 children, 321 males (50.2\%) and 318 females (49.8\%), participated in this study $(91.3 \%$ participation rate). Failure to participate was mostly attributed to denied permission by guardians.

Participants were predominantly white and more than half of the caregivers had a high level of education. Most parents had a household income $\leq 3 \mathrm{BMW}$. A prevalence of $21.6 \%$ was found for regular use of dental services (Table 1).

Table 1. Individual and contextual level characteristics of the sample.

\begin{tabular}{|c|c|c|}
\hline Variable & $n$ & $\%$ \\
\hline \multicolumn{3}{|l|}{ Individual Level (Child) } \\
\hline \multicolumn{3}{|l|}{ Gender ( $n=639)$} \\
\hline Male & 321 & 50.2 \\
\hline Female & 318 & 49.8 \\
\hline \multicolumn{3}{|l|}{ Age $(n=639)$} \\
\hline$\leq 1$ year & 129 & 20.2 \\
\hline 2 years & 124 & 19.4 \\
\hline 3 years & 161 & 25.2 \\
\hline$\geq 4$ years & 225 & 35.2 \\
\hline \multicolumn{3}{|l|}{ Skin color $(n=639)$} \\
\hline White & 501 & 78.4 \\
\hline Black & 138 & 21.2 \\
\hline \multicolumn{3}{|l|}{ Household income $(n=602)$} \\
\hline Less than 1 BMW & 158 & 26.2 \\
\hline Between 1 BMW and 2 BMW & 151 & 25.1 \\
\hline Between 2 BMW and 2 BMW & 171 & 28.4 \\
\hline More than 3 BMW & 122 & 20.3 \\
\hline \multicolumn{3}{|l|}{ Mother's schooling ( $n=633$ ) } \\
\hline$\geq 8$ years & 357 & 56.4 \\
\hline$<8$ years & 276 & 43.6 \\
\hline \multicolumn{3}{|l|}{ Father's schooling $(n=601)$} \\
\hline$\geq 8$ years & 321 & 53.4 \\
\hline$<8$ years & 280 & 46.6 \\
\hline \multicolumn{3}{|c|}{ Mothers' participation in school $(\mathrm{n}=632)$} \\
\hline Yes & 247 & 39.1 \\
\hline No & 385 & 60.9 \\
\hline \multicolumn{3}{|l|}{ Dental caries $(n=639)$} \\
\hline$\leq 4$ decayed teeth & 551 & 86.2 \\
\hline$>4$ decayed teeth & 88 & 13.7 \\
\hline \multicolumn{3}{|l|}{ Contextual level (Neighborhood) } \\
\hline \multicolumn{3}{|l|}{ Workers' association ( $\mathrm{n}=639)$} \\
\hline Present & 245 & 38.4 \\
\hline Absent & 394 & 63.7 \\
\hline \multicolumn{3}{|l|}{ Presence of Dentists ( $n=639$ ) } \\
\hline Present & 548 & 85.8 \\
\hline Absent & 91 & 14.2 \\
\hline
\end{tabular}


Individual and contextual factors influencing dental health care utilization by preschool children: a multilevel analysis

Table 2. Unadjusted assessment of the association of dental health care use among preschool children with individual and contextual-level variables.

\begin{tabular}{|c|c|c|c|}
\hline \multirow{2}{*}{ Variable } & \multirow{2}{*}{$\mathrm{n}$} & \multicolumn{2}{|c|}{ Have never gone to the dentist } \\
\hline & & n (\%) & OR $(95 \% \mathrm{Cl})$ \\
\hline \multicolumn{4}{|l|}{ Individual-level variables } \\
\hline Gender & 639 & 497 (78.39) & \\
\hline Male & 321 & 247 (77.39) & 1 \\
\hline Female & 318 & $250(79.62)$ & $1.15(0.79-1.68)$ \\
\hline Age (year) & 639 & 497 (78.39) & \\
\hline$\leq 1$ & 129 & $114(89.06)$ & 1 \\
\hline 2 & 124 & $104(84.55)$ & $0.67(0.32-1.40)$ \\
\hline 3 & 161 & $128(80.50)$ & $0.80(0.25-1.00)$ \\
\hline$\geq 4$ & 225 & $151(67.41)$ & $0.25(0.13-0.47)$ \\
\hline Skin color & 639 & 497 (78.39) & \\
\hline White & 501 & $394(78.96)$ & 1 \\
\hline Black & 138 & $103(76.30)$ & $0.85(0.54-1.34)$ \\
\hline Household income & 602 & 468 (78.39) & \\
\hline Less than $1 \mathrm{BMW}$ & 158 & $134(85.90)$ & 1 \\
\hline Between $1 \mathrm{BMW}$ and $2 \mathrm{BMW}$ & 151 & $116(77.85)$ & $0.57(0.31-1.04)$ \\
\hline Between 2 BMW and 2 BMW & 171 & $132(77.65)$ & $0.57(0.32-1.01)$ \\
\hline More than 3 BMW & 122 & $86(70.49)$ & $0.39(0.21-0.71)$ \\
\hline Mother's schooling (year) & 633 & $492(78.34)$ & \\
\hline$\geq 8$ & 357 & $262(73.80)$ & 1 \\
\hline$<8$ & 276 & $230(84.25)$ & $1.89(1.26-2.83)$ \\
\hline Father's schooling (year) & 601 & $465(77.89)$ & \\
\hline$\geq 8$ & 321 & $233(72.81)$ & 1 \\
\hline$<8$ & 280 & $232(83.75)$ & $1.92(1.28-2.88)$ \\
\hline Mothers' participation in school & 632 & 491 (78.31) & \\
\hline Yes & 247 & $172(69.92)$ & 1 \\
\hline No & 385 & 319 (83.73) & $2.21(1.50-3.25)$ \\
\hline Dental caries & 639 & 497 (78.39) & \\
\hline$<4$ decayed teeth & 551 & $439(80.40)$ & 1 \\
\hline$\geq 4$ decayed teeth & 88 & $58(65.91)$ & $0.47(0.28-0.76)$ \\
\hline \multicolumn{4}{|c|}{ Contextual-level variables (children living in the neighborhood) } \\
\hline Workers' association & 639 & 497 (78.39) & \\
\hline Present & 245 & $176(72.43)$ & 1 \\
\hline Absent & 394 & $321(82.10)$ & $1.74(1.19-2.55)$ \\
\hline Presence of Dentists & 639 & 497 (78.39) & \\
\hline Present & 548 & $425(78.13)$ & 1 \\
\hline Absent & 91 & $72(80.00)$ & $1.12(0.64-1.95)$ \\
\hline
\end{tabular}


Table 3. Multilevel Adjusted Assessment of dental health care use among preschool children associating individual and contextual variables.

\begin{tabular}{|c|c|c|c|}
\hline \multirow{2}{*}{ Fixed effects } & Model 1 (“null”) & Model 2 & Model 3 \\
\hline & \multicolumn{3}{|c|}{$\mathrm{OR}(\mathrm{Cl} 95 \%)$} \\
\hline Intercept & $3.55(2.73-4.63)$ & $6.62(2.75-15.93)$ & $4.86(1.96-12.07)$ \\
\hline \multicolumn{4}{|l|}{ Individual level (child) } \\
\hline \multicolumn{4}{|l|}{ Gender } \\
\hline Male & & 1 & 1 \\
\hline Female & & $1.08(0.71-1.64)$ & 1.07 (0.70-1.63) \\
\hline \multicolumn{4}{|l|}{ Age (year) } \\
\hline$\leq 1$ & & 1 & 1 \\
\hline 2 & & $0.74(0.34-1.62)$ & $0.76(0.34-1.66)$ \\
\hline 3 & & $0.59(0.29-1.21)$ & $0.59(0.29-1.22)$ \\
\hline$\geq 4$ & & $0.32(0.16-0.64)$ & $0.33(0.17-0.65)$ \\
\hline \multicolumn{4}{|l|}{ Skin color } \\
\hline White & & 1 & 1 \\
\hline Black & & $0.67(0.40-1.13)$ & $0.68(0.40-1.15)$ \\
\hline \multicolumn{4}{|l|}{ Mother's schooling (year) } \\
\hline$\geq 8$ & & 1 & 1 \\
\hline$<8$ & & $1.95(1.19-3.21)$ & $1.91(1.16-3.15)$ \\
\hline \multicolumn{4}{|l|}{ Household income } \\
\hline Less than $1 \mathrm{BMW}$ & & 1 & 1 \\
\hline Between 1 BMW and 2 BMW & & $0.63(0.33-1.18)$ & $0.65(0.34-1.22)$ \\
\hline Between 2 BMW and 2 BMW & & $0.67(0.35-1.26)$ & $0.72(0.38-1.36)$ \\
\hline More than $3 \mathrm{BMW}$ & & $0.49(0.24-0.99)$ & $0.52(0.26-1.06)$ \\
\hline \multicolumn{4}{|l|}{ Mothers' participation in school } \\
\hline Yes & & 1 & 1 \\
\hline No & & $1.76(1.15-2.71)$ & $1.80(1.17-2.77)$ \\
\hline \multicolumn{4}{|l|}{ Dental caries } \\
\hline$\leq 4$ decayed teeth & & 1 & 1 \\
\hline$>4$ decayed teeth & & $0.50(0.28-0.89)$ & $0.51(0.29-0.91)$ \\
\hline \multicolumn{4}{|l|}{ Contextual level: Neighbourhood } \\
\hline \multicolumn{4}{|l|}{ Workers' association } \\
\hline Present & & & 1 \\
\hline Absent & & & $1.65(1.04-2.60)$ \\
\hline \multicolumn{4}{|l|}{ Presence of Dentists } \\
\hline Present & & & 1 \\
\hline Absent & & & $0.74(0.38-1.41)$ \\
\hline \multicolumn{4}{|l|}{ Random effects } \\
\hline Deviance (-2loglikelihood) & 6.584 .654 & 55.855 .884 & 55.380 .134 \\
\hline
\end{tabular}


Table 2 shows the unadjusted assessment of the associations of dental health care utilization with individual and contextual variables. The analysis included children's ages, household income, parent's schooling, mothers' participation in their children's school activities, dental caries, and presence of workers' associations in the neighborhood as the main outcome covariates.

After adjusting for the individual covariates (Table 3 - Model 1), children's ages, household income, mother's schooling, mothers' participation in their children's school activities, and dental caries were identified as individual determinants of dental health service utilization. These variables remained associated with the outcome after adding the contextual variables in the model (Model3). A higher use of dental health services was observed among those living in neighborhoods with workers' associations.

\section{Discussion}

International guidelines recommend that infants have an initial oral health evaluation in the first year of life. ${ }^{22,23}$ Evidence suggests that an early visit to the dentist (in the first year of life) should help prevent dental disease. ${ }^{6,24}$ Moreover, early educational oral health programs for mothers could increase the use of dental services by preschool children. ${ }^{25}$ However, previous studies showed that dental care utilization by preschool children is low and is associated with socioeconomic factors. ${ }^{3,4,5,26}$

In our study, socioeconomic factors were related to the use of dental care, as reported by other authors. ${ }^{3,4,5,26}$ The current study considered household income and parents' schooling as proxies for socioeconomic status, which were identified as individual determinants for the outcome. Notwithstanding, only mother's schooling was fitted into the final model after adjustment for contextual variables. Children whose mothers did not complete primary education were less likely to use dental services. It is known that poor educational level may lead to low income, unemployment, and poor occupational status. Financial costs and low level of information about the importance of oral health could be a hindrance to dental care. ${ }^{27}$ Table 3 shows that socioeconomic variables affected the use of oral health services at both individual and contextual levels. This finding confirms previous reports on the importance of investigating the impact of contextual factors on oral health outcomes. ${ }^{8,9,10,28}$

Moreover, most children who participated in our study had their first dental visit after the age of 4 years. Only 14 children went to the dentist before their first year of life, as recommended by international guidelines. ${ }^{22,23}$ These findings could be related to socioeconomic status and availability of dental care. ${ }^{29,30}$ In other words, a social gradient in health is present in dental service utilization.

This study also verified that mothers' participation in their children's school activities positively influenced dental care utilization. Participative mothers were more likely to take their children to the dentist. We suggest that mothers who keep track of the school activities are more concerned with everything that involves their children, including oral health. Socioeconomic factors could be part of this relation. Generally, mothers with a higher family income are better informed and can afford to monitor their children in all aspects. Therefore, participation in children's school activities could be strongly modulated by socioeconomic status. Nevertheless, further studies are needed for comparison of our results. To our knowledge, no earlier study had investigated this association in the literature.

Furthermore, a significant effect of social context on dental care utilization by preschool children was verified in our analysis. In the final model, the number of workers' associations located in the neighborhood could be noted at the contextual level, as children who lived in areas with workers' associations were more likely to go to the dentist. This contextual variable could be related to social support. Neighborhood connection, such as time spent with friends that attend the meetings of an association can be a proxy for social support and social capital. ${ }^{31,32}$ We suggest that frequency of contact with friends may reduce social isolation, which plays an important role in maintaining oral health. In other words, oral health behaviors can be influenced by social controls. Participation in workers' associations implies interaction between 
individuals, which may suggest the transmission of good ideas and healthier choices. ${ }^{13,33}$

Regarding contextual variables, in this study, the prevalence of dental health care utilization was not influenced by the presence of dentists in the neighborhood (Table 3), which is in disagreement with a previous study ${ }^{12}$ that analyzed data from the six largest metropolitan counties in Ohio, USA. Our study was conducted only in Santa Maria, Brazil, where there are a large number of dentists per capita. Almost all the participants in our study lived in areas where there were dentists. This could possibly explain our findings.

The cross-sectional design could be a possible limitation of our study. Therefore, our results should be interpreted along with the limitations of this type of study. Moreover, the number of workers' associations was provided by the local authorities and it is possible that it might not be perfectly correct, despite the fact that this information has been used in official local publications.

\section{References}

1. Medina-Solís CE, Maupomé G, Avila-Burgos L, Hijar-Medina M, Segovia-Villanueva A, Pérez-Núñez

R. Factors influencing the use of dental health services by preschool children in Mexico. Pediatr Dent. 2006;28(3):285-92.

2. Noro LR, Roncalli AG, Mendes Júnior FI, Lima KC. [Use of dental care by children and associated factors in Sobral, Ceara State, Brazil]. Cad Saúde Pública. 2008;24(7):1509-16. Portuguese. https://doi.org/10.1590/S0102-311X2008000700005

3. Ardenghi TM, Vargas-Ferreira F, Piovesan C, Mendes FM. Age of first dental visit and predictors for oral healthcare utilisation in preschool children. Oral Health Prev Dent. 2012;10(1):17-27.

4. Machry RV, Tuchtenhagen S, Agostini BA, da Silva Teixeira CR, Piovesan C, Mendes FM et al. Socioeconomic and psychosocial predictors of dental healthcare use among Brazilian preschool children. BMC Oral Health. 2013;13(1):60. https://doi.org/10.1186/1472-6831-13-60

5. Rodrigues LA, Martins AM, Silveira MF, Ferreira RC, Souza JG, Silva JM et al. [The use of dental services among preschool children: a population-based study]. Cien Saúde Colet. 2014;19(10):4247-56. Portuguese. https://doi.org/10.1590/1413-812320141910.13382013
In our analysis, we used the multilevel approach to verify the extent to which the outcome is accounted for by contextual and individual variables. We adjusted the models according to the region where the children lived. Recent research has reported that contextual variables, such as city-level variables (suburbs with the worst social exclusion indices; socially-deprived areas), can negatively influence oral health outcomes. ${ }^{34,34}$ Therefore, assessing the characteristics of the neighborhood in which children live is important for the investigation into oral health inequalities.

\section{Conclusion}

In conclusion, individual and contextual variables are associated with dental health care utilization by preschool children. Therefore, these variables must be taken into consideration for redirection of resources allocated to public health and for the formulation of oral health policies.

6. Darmawikarta D, Chen Y, Carsley S,

Birken CS, Parkin PC, Schroth RJ et al. Factors

associated with dental care utilization in early

childhood. Pediatrics. 2014;133(6):e1594-600.

https://doi.org/10.1542/peds.2013-3725

7. Piovesan C, Antunes JL, Guedes RS, Ardenghi TM. Influence of self-perceived oral health and socioeconomic predictors on the utilization of dental care services by schoolchildren. Braz Oral Res. 2011;25(2):143-9. https://doi.org/10.1590/S1806-83242011005000004

8. Pattussi MP, Hardy R, Sheiham A. The potential impact of neighborhood empowerment on dental caries among adolescents. Community Dent Oral Epidemiol. 2006;34(5):344-50. https://doi.org/10.1111/j.1600-0528.2006.00283.x

9. Celeste RK, Nadanovsky P, De Leon AP. [Association between preventive care provided in public dental services and caries prevalence]. Rev Saúde Pública. 2007;41(5):830-8. Portuguese. https://doi.org/10.1590/S0034-89102007000500018

10. Barriuso Lapresa L, Sanz Barbero B. [Multilevel analysis of the use of oral health services by the pediatric population]. Gac Sanit. 2011;25(5):391-6. Spanish. https://doi.org/10.1016/j.gaceta.2011.03.011 
11. Lopez R, Frydenberg M, Baelum V. Contextual effects in the occurrence of periodontal attachment loss and necrotizing gingival lesions among adolescents. Eur J Oral Sci. 2009;117(5):547-54. https://doi.org/10.1111/j.1600-0722.2009.00658.x

12. Lee W, Kim SJ, Albert JM, Nelson S. Community factors predicting dental care utilization among older adults. J Am Dent Assoc. 2014;145(2):150-8. https://doi.org/10.14219/jada.2013.22

13. Aida J, Ando Y, Oosaka M, Niimi K, Morita M. Contributions of social context to inequality in dental caries: a multilevel analysis of Japanese 3-year-old children. Community Dent Oral Epidemiol. 2008;36(2):149-56. https://doi.org/10.1111/j.1600-0528.2007.00380.x

14. Pattussi MP, Hardy R, Sheiham A. Neighborhood social capital and dental injuries in Brazilian adolescents. Am J Public Health. 2006;96(8):1462-8. https://doi.org/10.2105/AJPH.2005.066159

15. Piovesan C, Ardenghi TM, Guedes RS, Ekstrand KR, Braga MM, Mendes FM. Activity assessment has little impact on caries parameters reduction in epidemiological surveys with preschool children. Community Dent Oral Epidemiol. 2013;41(3):204-11. https://doi.org/10.1111/cdoe.12004

16. Piovesan C, Moro BL, Lara JS, Ardenghi TM, Guedes RS, Haddad AE et al. Laboratorial training of examiners for using a visual caries detection system in epidemiological surveys. BMC Oral Health. 2013;13(1):49. https://doi.org/10.1186/1472-6831-13-49

17. Ismail AI, Sohn W, Tellez M, Amaya A, Sen A, Hasson H et al. The International Caries Detection and Assessment System (ICDAS): an integrated system for measuring dental caries. Community Dent Oral Epidemiol. 2007;35(3):170-8. https://doi.org/10.1111/j.1600-0528.2007.00347.x

18. Pitts N. "ICDAS": an international system for caries detection and assessment being developed to facilitate caries epidemiology, research and appropriate clinical management. Community Dent Health. 2004;21(3):193-8.

19. Braga MM, Oliveira LB, Bonini GA, Bönecker $M$, Mendes FM. Feasibility of the International Caries Detection and Assessment System (ICDAS-II) in epidemiological surveys and comparability with standard World Health Organization criteria. Caries Res. 2009;43(4):245-9. https://doi.org/10.1159/000217855

20. Instituto Brasileiro de Geografia e Estatística - IBGE. Pesquisa nacional por amostra de domicílios: síntese de indicadores 2011 [cited 2011 Dec 8]. Disponível em: http://www.ibge. gov.br/home/estatistica/populacao/trabalhoerendimento/ pnad2011/sintese_defaultpdf_familias.shtm

21. Diez-Roux AV. Multilevel analysis in public health research. Annu Rev Public Health. 2000;21(1):171-92. https://doi.org/10.1146/annurev.publhealth.21.1.171

22. American Academy on Pediatric Dentistry. Guideline on infant oral health care. Pediatr Dent. 2008;30(7 Suppl):90-3.
23. Canadian Dental Association. CDA position on the first visit to the dentist. 2012 [cited 2016 Mar 18]. Available from: http:// www.cda-adc.ca/en/about/position_statements/firstvisit/

24. Lee JY, Bouwens TJ, Savage MF, Vann WF Jr. Examining the cost-effectiveness of early dental visits. Pediatr Dent. 2006;28(2):102-5.

25. Plutzer K, Keirse MJ. Influence of first-time mothers' early employment on severe early childhood caries in their child. Int J Pediatr. 2012;2012:820680. https://doi.org/10.1155/2012/820680

26. Kramer PF, Ardenghi TM, Ferreira S, Fischer LA, Cardoso L, Feldens CA. [Use of dental services by preschool children in Canela, Rio Grande do Sul State, Brazil]. Cad Saúde Pública. 2008;24(1):150-6. Portuguese. https://doi.org/10.1590/S0102-311X2008000100015

27. Kelly SE, Binkley CJ, Neace WP, Gale BS. Barriers to care-seeking for children's oral health among low-income caregivers. Am J Public Health. 2005;95(8):1345-51. https://doi.org/10.2105/AJPH.2004.045286

28. Guedes RS, Piovesan C, Antunes JL, Mendes FM, Ardenghi TM. Assessing individual and neighborhood social factors in child oral health-related quality of life: a multilevel analysis. Qual Life Res. 2014;23(9):2521-30. https://doi.org/10.1007/s11136-014-0690-z

29. Jiang H, Petersen PE, Peng B, Tai B, Bian Z. Self-assessed dental health, oral health practices, and general health behaviors in Chinese urban adolescents. Acta Odontol Scand. 2005;63(6):343-52. https://doi.org/10.1080/00016350500216982

30. Sohn W, Ismail A, Amaya A, Lepkowski J. Determinants of dental care visits among low-income African-American children. J Am Dent Assoc. 2007 Mar;138(3):309-18. https://doi.org/10.14219/jada.archive.2007.0163

31. Costa DL, Matthew EK. Understanding the American decline in social capital, 1952-1998. Kyklos. 2003;56(1):17-46. https://doi.org/10.1111/1467-6435.00208

32. Merchant AT, Pitiphat W, Ahmed B, Kawachi I, Joshipura K. A prospective study of social support, anger expression and risk of periodontitis in men. J Am Dent Assoc. 2003;134(12):1591-6. https://doi.org/10.14219/jada.archive.2003.0104

33. Aida J, Kuriyama S, Ohmori-Matsuda K, Hozawa A, Osaka K, Tsuji I. The association between neighborhood social capital and self-reported dentate status in elderly Japanese: the Ohsaki Cohort 2006 Study. Community Dent Oral Epidemiol. 2011;39(3):239-49. https://doi.org/10.1111/j.1600-0528.2010.00590.x

34. Vazquez FL, Cortellazzi KL, Kaieda AK, Bulgareli JV, Mialhe FL, Ambrosano GM et al. Individual and contextual factors related to dental caries in underprivileged Brazilian adolescents. BMC Oral Health. 2015;15(1):6. https://doi.org/10.1186/1472-6831-15-6

35. Roncalli AG, Tsakos G, Sheiham A, Souza GC, Watt RG. Social determinants of dental treatment needs in Brazilian adults. BMC Public Health. 2014;14(1):1097. https://doi.org/10.1186/1471-2458-14-1097 